\title{
Removal of Cadmium (II), Chromium (III), and Lead (II) Heavy Metal Ions from Water by Graft Copolymerization of Acrylonitrile onto Date Palm Fiber Using $\mathrm{H}_{2} \mathrm{O}_{2} / \mathrm{Fe}^{++}$as an Initiator
}

\author{
Faraj Ahmad Abuilaiwi (iD) ${ }^{1,2}$ \\ ${ }^{1}$ Department of Chemistry, College of Science, University of Hafr Al Batin, P.O. Box 1803, Hafr Al Batin 31991, Saudi Arabia \\ ${ }^{2}$ Affiliated Colleges at Hafr Al Batin, King Fahd University of Petroleum and Minerals, P.O. Box 1803, \\ Hafr Al Batin 31991, Saudi Arabia
}

Correspondence should be addressed to Faraj Ahmad Abuilaiwi; faraj@uhb.edu.sa

Received 28 June 2020; Revised 30 September 2020; Accepted 4 October 2020; Published 21 October 2020

Academic Editor: Mehdi Salami-Kalajahi

Copyright (c) 2020 Faraj Ahmad Abuilaiwi. This is an open access article distributed under the Creative Commons Attribution License, which permits unrestricted use, distribution, and reproduction in any medium, provided the original work is properly cited.

\begin{abstract}
The study is aimed at assessing how the date palm wood fibers (DPWF) can be used for the removal of heavy metals from water. The study involved examination of the radical polymerization and graft polymerization parameters such as reaction period, reaction time, monomer volume, amount of the catalyst, and concentration of initiator to obtain the maximum yield of graft polymerization. Fiber and copolymer were characterized using SEM and FT-IR spectroscopy to ensure the completion of polymerization. Hydroxylamine hydrochloride was used for treating the grafted copolymers for the preparation of polyamidoxime chelating resin, which was then examined for removing the heavy metal ions. Different resin dosages, contact time, and initial concentrations were used, and the batch technique experiment was utilized. The study also applied the Langmuir and Freundlich isotherm model, and Langmuir was found to be better. The absorption ability was found to be better for polyamidoxime resin for metal ions of cadmium (II), chromium (III), and lead (II).
\end{abstract}

\section{Introduction}

Discharge of heavy metals in the industrial effluents has increased the problem of water pollution [1]. Previous studies have revealed that nonbiodegradable heavy metals tend to accumulate in the bodies of living organisms and, for the same reason, they are more hazardous as compared to other water pollutants [2]. Copper, silver, zinc, selenium, cadmium, mercury, lead, nickel, chromium, tin, iron, arsenic, gold, molybdenum, cobalt, manganese, aluminum, etc. are some commonly found heavy metals [3], which are proved to be harmful for humans and other living organisms [1]. Fu and Wang [4] stated that regular deposition of heavy metal subsequently causes severe damage to the central nervous system, skin, kidneys, teeth, liver, or lungs and could also lead to death. Additionally, the removal of heavy metals is also challenging on account of their nonbiodegradability [5].
In order to address this issue, researchers are focusing on the use of natural and bio-based materials [6]. Various kinds of biobased materials have been introduced, which may be based on cellular fibers, wood, or protein and help in reducing the harmful effects caused by nonbiodegradable elements [7]. Similarly, for the removal of heavy metals from aqueous solution, different methods, including precipitation and membrane processes: reverse osmosis, ion exchange, ultrafiltration, and more, are being used [8]. The use of precipitation after coagulation is limited on account of high sludge volume. Studies have identified membrane filtration as a cost-effective way of ensuring the removal of metal ions; however, its cost is a major impediment in its implementation $[9,10]$.

Kanamarlapudi et al. [10] found absorption as an efficient, simple, and effective approach in the removal of heavy metals from the wastewater; however, its high cost is also 
major challenge in its implementation. These challenges instigated scholars and researchers to find or develop costeffective, eco-friendly, and nonconventional absorbents [9]. Recently, the interest in the use of plant-based fiber has increased, which is commercially in the production of polymer composites [1]. These composites can be used for removing the heavy metal ions from water especially when conventional methods are proved ineffective [11]. In order to satisfy and solve the above-mentioned problems, some natural materials such as cellulose, chitosan, chitin, and their derivatives have been specified as good and inexpensive options because of their economic efficiency, absorbent properties, safety, and biodegradability.

Ion exchange is a reaction in which free mobile ions of a solid are exchanged with different ions of identical charge in a solution. The exchanger contains an open network structure, either organic or inorganic, which carries the ions and let ions to pass through it. Ion exchangers may be organic or inorganic and are natural or synthetic materials such as synthetic resins which function as ion exchangers based on three-dimensional organic networks bearing charged or potentially charged groups [12]. Past research has shown increased interest in the use of date palm as a biodegradable material [13].

Recently, many studies have focused on exploring an alternative metal adsorbent and grafted polymers. Grafting is the method in which functional monomers are covalently bonded to the backbone polymer chain [14-17]. Graft polymerization is significant as it permits implementing different functions of the grafted monomer on the parent polymer while retaining the mechanical features of the parent polymer. Radiation-induced grafting technique is dominant over all other approaches implemented to initiate graft copolymerization such as ultraviolet light, decomposition of chemical initiators, oxidation of polymers, plasma treatment, and ionizing radiation because of its extensive penetration into the polymer matrix and its rapid and homogeneous development of radicals $[18,19]$.

Date palm ("Phoenix dactylifera") is abundantly grown throughout Saudi Arabia, and its global production rate is $42 \%$. It is an edible fruit with a papery skin and a single, long, narrow, hard seed. There are many uses of date palm wood; for instance, it is used as posts and rafters for huts because it is lighter than coconut. It is also used in the construction of aqueducts, bridges, and parts of boats and dhows. Moreover, the tree residues are used as fuel [20]. Date palm contains three major components: cellulose, lignin, hemicellulose, and other minor constituents such as protein and oil [21].

The focus of this is on date palm on account of its abundance, cost-effectiveness, and renewability in the Kingdom of Saudi Arabia. Its fiber produces biodegradable materials when treated with certain monomers and can be obtained at low costs in comparison with the costly plastic materials which are commonly used for removing metal ions from water. The limitations associated with heavy metals have led to extensive researches for the production of costeffective alternatives which should be excessively available as waste materials. In the current study, the effectiveness of date palm fibers as low-cost bioabsorbent of heavy metals has been studied, with a focus on the impacts of the different reaction parameters that influence the adsorption efficiency.
1.1. Modified Date Palm as Adsorbent of Heavy Metals. In 30 countries, approximately 120 million date palm trees are cultivated covering an area of 800,000 hectares [22, 23]. The investigation of the regional distribution shows that approximately 60 million date palm trees are located in Iran, Iraq, Oman, Pakistan, Saudi Arabia, Yemen, Bahrain, and Turkmenistan, and almost 32.5 million date palm trees are located in Africa. El-Hendawy [24] investigated the adsorption capacities of date pit-activated carbons with respect to $\mathrm{Pb}^{2+}$ and $\mathrm{Cd}^{2+}$. Data were compatible with the Langmuir model, which substantially contributed to the increase in adsorption capacity in comparison with raw date pits and subsequently led to the increase in the adsorption of lead. The consumption was higher than cadmium due to its suitable $\mathrm{pH}$ for complexation or deposition and lower solubility. el Nemr et al. [25] assessed the removal of toxic chromium (VI) from different aqueous solutions with the help of an adsorbent containing activated carbon obtained date palm seed. The optimum $\mathrm{pH}$ for absorption was 1.0 , and the increase in $\mathrm{pH}$ decreased the adsorption percentage. $120.48 \mathrm{mg} / \mathrm{g}$ was the maximum adsorption capacity for chromium (VI), and the equilibrium was obtained in $180 \mathrm{~min}$ due to the fast adsorption process. Studies have shown that the use of date stone and palm tree waste increases the $\mathrm{Cu}^{2+}$ adsorption, where equilibrium was obtained within $120 \mathrm{~min}[26,27]$. Hilal et al. [28] stated that maximum absorption capacity of activated date pits was at a $\mathrm{pH}$ of $5.8 \pm 0.5$, which was five times greater than that of the raw date pits.

Abdulkarim and Al-Rub [29] studied the removal of lead (II) onto activated carbons, and 8-hydroxyquinoline modified activated carbons from date pits. The adsorption capacity was high in both the carbons; however, no significant improvement was found in adsorption after modification. Removal of $\mathrm{Pb}$ (II) ions using activated carbons was increased with an increase in $\mathrm{pH}$. This process followed pseudo-second-order kinetics. The Langmuir and Freundlich models showed good agreement from the equilibrium data for the adsorption of lead (II) ions. Yadav et al. [30] showed that date palm fibers can remove 99.955 chromate anions $\left(\mathrm{Cr}^{6+}\right)$ from a $100 \mathrm{mgL}^{-1}$ solution with the use of a small absorbent dosage, i.e., $1.2 \mathrm{~g} \mathrm{~L}^{-1}$.

Tunisian date stones activated via phosphoric acid were used for the removal of copper (II) from aqueous solutions. The best-activated carbon for the removal process was obtained with $60 \%$ phosphoric acid and an impregnation ratio of 1.75 at $450^{\circ} \mathrm{C}$. Dubinin-Kaganer-Radushkevich and Langmuir adsorption isotherm models were enough to explain the adsorption of copper (II) onto activated carbon (q) which was found to be $31.25 \mathrm{mg} / \mathrm{g}$. Bouhamed et al. [26] suggested a chemisorption process from kinetic data that were compatible with the pseudo-second-order kinetic model.

el-Shafey and al-Kindy [31] modified leaflets of date palm using the sulphuric acid method at $170^{\circ} \mathrm{C}$. They suggested that the hot sulphuric acid dehydrates and induces reduction property in carbon. This carbon was used to remove copper and silver from aqueous solution using various parameters such as contact time, $\mathrm{pH}$, temperature, and metal concentration. Adsorption of copper was greater as compared to the 
adsorption of silver as the equilibrium was reached within $\sim 2 \mathrm{~h}$ and $\sim 60 \mathrm{~h}$, respectively. The adsorption of copper was carried out through the diffusion-controlled ion exchange process; however, the value of activation energy of silver indicated chemisorption of silver ions into carbon.

The adsorption capacities of raw date pits and $\mathrm{CO}_{2}$ activated date pits were compared with respect to the adsorption of copper and zinc ions. Banat et al. [32] found adsorption of both copper and zinc onto raw date pits higher than adsorption onto activated date pit carbon. This attributed to the difference in the surface functional groups of date pits and activated date pits. The heating during the activation process may have destroyed the functional groups that facilitate binding of zinc and copper. The removal of copper was better in comparison with the removal of zinc with respect to both the materials on account of its small ionic radius that facilitates an easy movement into porous surface. The best result was obtained at $\mathrm{pH}=5$ and temperature at $25^{\circ} \mathrm{C}$.

\section{Methodology}

2.1. Materials and Reagents. A nonwoven polyethylene fabric was used as a trunk polymer for graft polymerization; the material was obtained from Kurashiki MFG Co. Monomer acrylonitrile (BDH, England) was used for grafting onto a trunk polymer. Sodium carbonate, methanol, acetone, and sulphuric acid were obtained from Merck, Germany, and hydroxyl amine hydrochloride was obtained from SigmaAldrich, USA. Cadmium (II), lead (II) acetate trihydrate (Merck, Germany), and chromium (III) (Techno Pharmchem, India) were used for a metal adsorption study. Date palm fiber was obtained from a local market, and the size of the fiber was less than $200 \mu \mathrm{m}$. The fiber was washed two times with hot distilled water and acetone. The acetone was removed by heating the fiber in an oven at $60^{\circ} \mathrm{C}$.

2.2. FTIR Spectroscopy. Infrared (IR) spectra of the DPW, grafted DPW, and the poly (amidoxime) ion-exchange resin samples were recorded on a Fourier transform-IR spectrometer (Perkin-Elmer 1725, Norwalk, CT) using a $\mathrm{KBr}$ disk pellet.

2.3. Scanning Electron Microscopy (SEM). The SEM photographs of the fiber surfaces of grafted PAN onto DPW and ungrafted DPW fiber were captured using a scanning electron microscope model SEM JEOL 6400 (JEOL, Peabody, MA).

2.4. Preparation of a Chelating Resin Containing Polyamidoxime Groups. Hydroxylamine hydrochloride $\left(\mathrm{NH}_{2} \mathrm{OH} . \mathrm{HCl}\right)$ solution was prepared by dissolving $20 \mathrm{~g}$ $(0.288 \mathrm{~mol})$ of hydroxylamine hydrochloride in $300 \mathrm{ml}$ of a methanolic aqueous solution (methanol/water ratio $=80$ ). The hydrochloride content of $\mathrm{NH}_{2} \mathrm{OH} . \mathrm{HCl}$ was neutralized by the addition of $\mathrm{NaOH}$ solution, and the precipitated $\mathrm{NaCl}$ was removed by filtration. The grafted product was placed in a two-necked flask equipped with a condenser; the flask was placed in a thermostatic water bath, and the hydroxylamine solution was poured in it. The mixture was allowed to react at $70^{\circ} \mathrm{C}$ with continuous stirring for $180 \mathrm{~min}$. After completion of the reaction, the resin was filtered and washed several times with the methanolic solution. The resin was neutralized by treating it with $0.1 \mathrm{M} \mathrm{HCl}$ solution for $15 \mathrm{~min}$; afterwards, it was again filtered, washed several times with the methanolic solution, and then dried in an oven at a constant weight at $60^{\circ} \mathrm{C}$.

2.5. Sorption of Lead Cadmium and Chromium Ions Using the Batch Technique. The lead, cadmium, and chromium ion adsorption capacities of the resin were measured over the $\mathrm{pH}$ range of $1-6$. Thus, $\mathrm{ca} .0 .1 \mathrm{~g}$ of dried resin was placed in a series of $100 \mathrm{ml}$ polyethylene bottles and equilibrated with $20 \mathrm{ml}$ of distilled water. After adding $20 \mathrm{ml}$ of $0.1 \mathrm{M}$ sodium acetate buffer solution in each bottle, $10 \mathrm{ml}$ of $0.1 \mathrm{M}$ leadions solution was added. The resulting mixture was shaken for $24 \mathrm{~h}$ by a rotary shaker, and afterwards, $5 \mathrm{ml}$ of the supernatant was collected for the determination of metal-ions. An AGBC-903 atomic absorption spectrometer was used to determine the initial and final amounts of metal ions present in the solutions.

Blank experiments were performed, and the same experimental procedure was conducted for checking the adsorption level by the membrane filters and glass flasks for all adsorption tests. The kinetic samples were conducted in $1000 \mathrm{ml}$ batch reactors at 20.0 in deionized water. The flasks were vigorously and magnetically stirred for $1.5 \mathrm{~h}$ for hydrating the beet pulp to naturally maintain the $\mathrm{pH}$ at 5.5.

2.6. Graft Copolymerization. To prepare the fiber/PAN copolymer, $1.00 \mathrm{~g}$ DPW fiber was placed in $250 \mathrm{ml}$ threenecked flasks equipped with a stirrer and condenser and immersed into a thermostatic water bath. The DPW suspension was obtained by adding $100 \mathrm{ml}$ distilled water and $0.1 \mathrm{~g}$ ferrous ammonium sulphate with continuous stirring. Nitrogen purged through the DPW fiber slurry to remove oxygen during the reaction. After $30 \mathrm{~min}$, the required volume of 2.0 $\mathrm{M} \mathrm{H}_{2} \mathrm{O}_{2}$ was added and the mixture was mixed for $5 \mathrm{~min}$; afterwards, the required amounts of monomer (AN) were added into the mixture. The reaction mixture was stirred under nitrogen at the chosen temperature and for the predetermined reaction period. Immediately after the reaction, the reaction flask was cooled by placing it under running tap water, and the product was filtered. The crude product was washed thoroughly with distilled water and oven-dried at $60^{\circ} \mathrm{C}$ at a constant weight.

2.7. Removal of Polyacrylonitrile and Determination of Graft Level. The crude product was purified with $N, N$-dimethylformamide using a Soxhlet extractor for $48 \mathrm{~h}$ to remove the polyacrylonitrile (PAN). The pure grafted copolymers were then dried at $65^{\circ} \mathrm{C}$ at a constant weight. The following formula determined the percentage of grafting $(\mathrm{Pg})$ :

$$
\mathrm{Pg}=\frac{W_{2}-W_{1}}{W_{1}} \times 100
$$

where $W_{1}$ is the weight of the original DPW fibers in grams and $W_{2}$ is the weight of the grafted product after copolymerization and extraction [33]. 

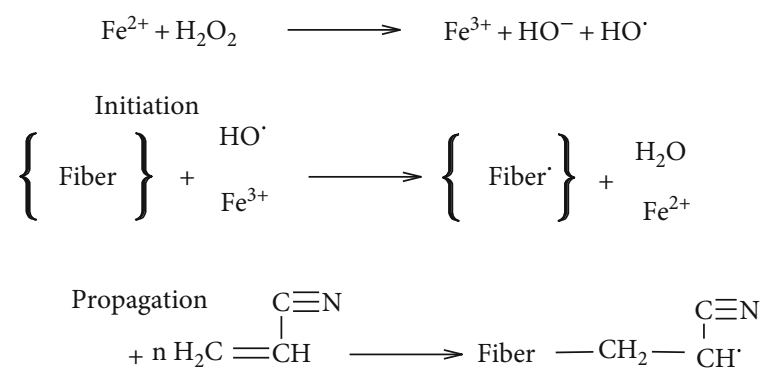

$\mathrm{M}$
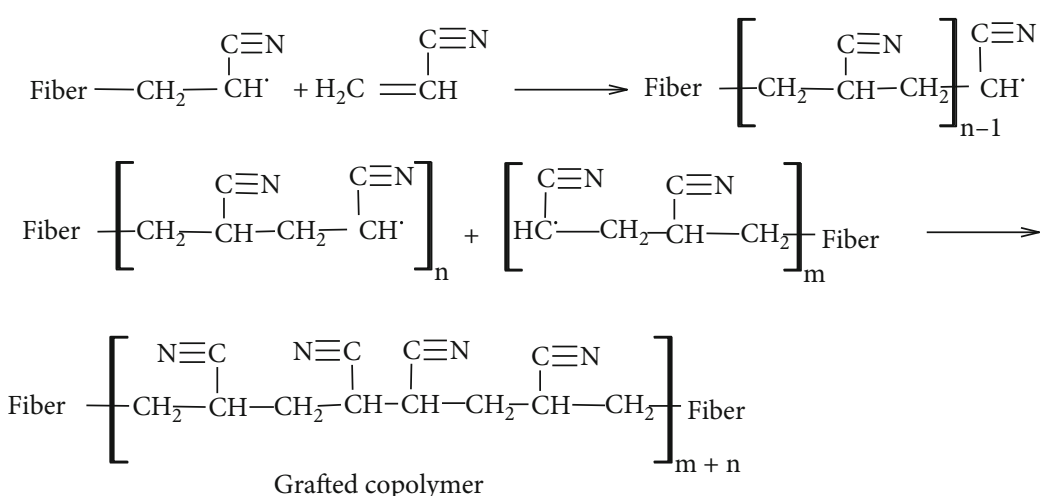

$$
\begin{array}{ll}
\text { Fiber }+(M)_{n}-M^{*} \longrightarrow & \text { Fiber }-(M)_{n} M \\
& \text { Grafted copolymer } \\
(M)_{n}-M^{*}+(M)_{n}-M^{\cdot} \longrightarrow & M-(M)_{2 n} M \\
\text { Homopolymer }
\end{array}
$$

FIGURE 1: Mechanism of graft copolymerization of acrylonitrile onto DPWF.

2.8. Graft Copolymerization. Date palm wood fiber (DPWF) was treated with a mixed solution of hydrogen peroxide and ferrous ammonium sulfate to initiate a free radical in the backbone of the fiber and provide cellulose macroradical. Graft copolymerization occurred after adding acrylonitrile $(\mathrm{AN})$ monomer to the mixture during which the cellulose macroradical broke the double bond in $\mathrm{AN}$ and a covalent bond between monomer and cellulose was formed, the chain initiated with continues creation of free radical on the AN. Chain grafting onto the cellulose was possible by adding AN monomer subsequently. The reaction was ultimately terminated either by the formation of a copolymer on account of the reaction of two macroradical or formation of poly(methacrylate) by the reaction of two monomer radicals. Figure 1 explains the whole process $[34,35]$.

2.9. Optimization of Grafted Polymerization Parameters. Effects of various parameters on the yield of grafted copolymerization were studied. These parameters included temperature, reaction time, monomer volume, cocatalyst amount, and concentration of initiator. All these parameters were studied separately to investigate the best conditions and to obtain the best yield.
2.9.1. Effect of Temperature. A wide range of temperatures was used to obtain the best yield of the grafted copolymer. Figure 2 illustrates the effect of temperature that increase in temperature from $30^{\circ} \mathrm{C}$ up to $75^{\circ} \mathrm{C}$ increases the $\%$ yield of grafting. This increase could be attributed to the increase of monomer diffusion into the active sites on the backbone of the substrate. If temperature goes above $75^{\circ} \mathrm{C}$, the monomer starts to evaporate, and hydrogen peroxide decomposes. This condition leads to creation of a huge number of free radicals, the yield of a homopolymer will increase, and \% of the grafted copolymer in pg will decrease $[36,37]$.

2.9.2. Effect of the Concentration of Initiator. The yield of grafted polymer is clearly affected by the concentration of the initiator. As shown in Figure 3, the \% of grafting increased with the increase in the concentration of the hydrogen peroxide as it increases the production of free radicals in the active sites of the fiber. At $0.03 \mathrm{M}$ concentration, $81 \%$ grafting was obtained. However, the grafting percentage decreased with further increase in the percentage of hydrogen peroxide because of the reaction between cellulose radicals before addition of monomers, and this reaction is the termination step. Moreover, at higher concentrations, the yield of homopolymer increases [34]. 


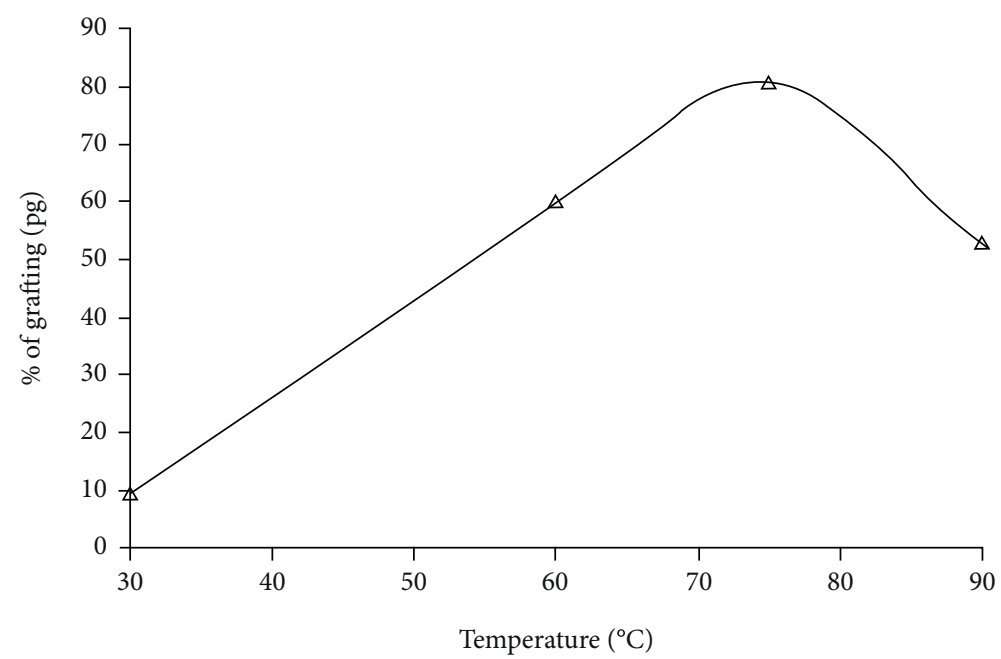

FiguRE 2: Effect of reaction temperature on the $\%$ of grafting in pg. Reaction time: $60 \mathrm{~min}, \mathrm{AN}: 8 \mathrm{ml}, \mathrm{H}_{2} \mathrm{O}_{2}: 0.03 \mathrm{M}, \mathrm{Fe}^{+2}: 0.3 \mathrm{mmol}$, and $(\Delta)$ : $\%$ of grafting.

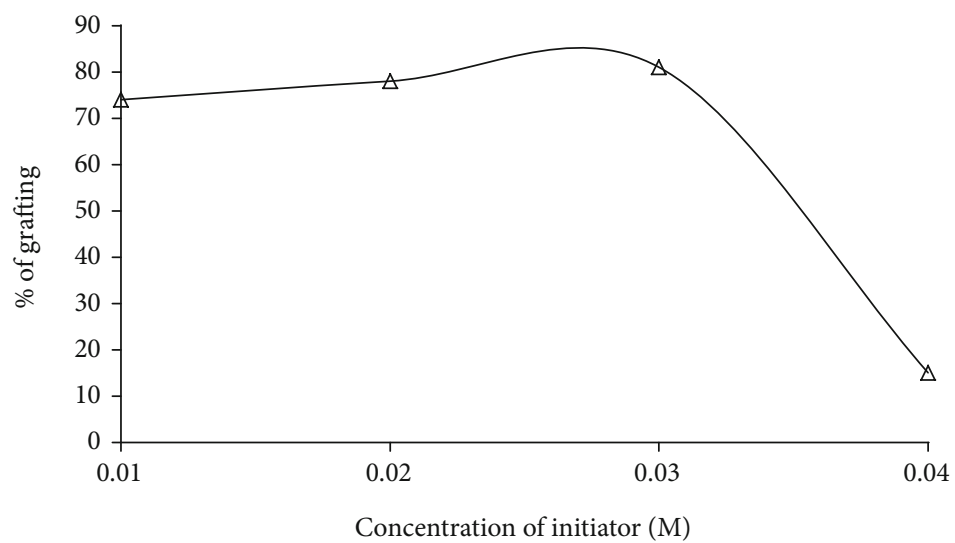

Figure 3: Effect of the amount of initiator $\mathrm{H}_{2} \mathrm{O}_{2}$ on the $\%$ of grafting. Reaction time: $60 \mathrm{~min}, \mathrm{AN}: 8 \mathrm{ml}$, temperature: $75^{\circ} \mathrm{C}, \mathrm{Fe}^{+2}: 0.3 \mathrm{mmol}$, and $(\Delta)$ : \% of grafting.

2.9.3. Effect of the Amount of Monomer. The percentage of grafting increased with the increasing volume of the (AN) monomer on account of the availability of a large number of monomer molecules reaching the active sites in the backbone of the fiber. However, as shown in Figure 4, increase in volume over $8 \mathrm{ml}$ decreased the percentage of grafting on account of the increased possibility of homopolymerization $[37,38]$.

2.9.4. Effect of Reaction Period. The percentage of grafting was found directly proportional to the increase in the reaction time, and it increases the time available to all monomer molecules to reach the active sites on the backbone; however, the maximum grafting yield was obtained with the reaction time of 60 minutes. Afterwards, all active sites were covered, and the concentration of all reaction species decreased and this accounted for the low yield of grafting which almost remains constant with increasing time [39]. This explanation is in line with the results shown in Figure 5.

2.9.5. Effect of the Amount of Catalyst. Small amount of ammonium ferrous sulphate $\left[\left(\mathrm{NH}_{4}\right)_{2} \mathrm{SO}_{4} \cdot \mathrm{FeSO}_{4} \cdot 6 \mathrm{H}_{2} \mathrm{O}\right]$ was found to be enough for the best yield of a product (Figure 6), where $0.306 \mathrm{mmol}$ of catalyst gave $81 \%$ of grafting product. This yield decreased with the increase in the amount of the catalyst on account of a large number of radicals produced by the decomposition of hydrogen per oxide. The reaction finally terminates due to the reaction between radicals and yield will decrease $[33,40]$.

2.10. Preparation of Polyamidoxime Resin. The AN-DPWF grafted copolymer containing nitrile group was treated with hydroxylamine hydrochloride at $\mathrm{pH} 11$ to change the nitrile group into amidoxime. This reaction was performed for 3 hours at $75^{\circ} \mathrm{C}$, and the ratio between grafted copolymer and hydroxylamine in methanolic solution was $1: 1$. The mechanism of this conversion is shown in Figure 7.

2.11. Characterization of AN-DPWF Grafted Copolymer and Resin. FT-IR spectra were obtained for DPWF, grafted copolymer, and amidoxime resin to confirm the completion of polymerization and conversion of grafted copolymer into the chelating resin. In Figure 8, the same characteristic adsorption bands for DPWF, such as broad absorption band 


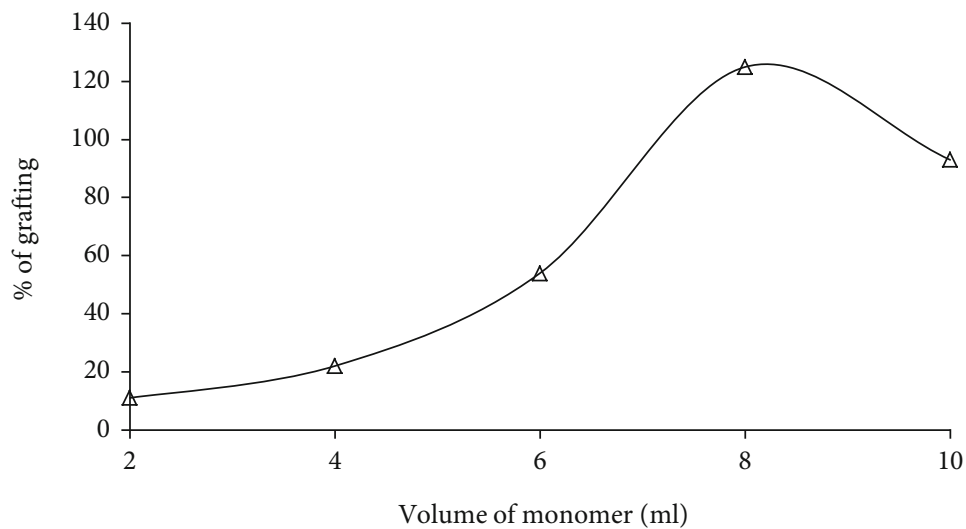

FIGURE 4: Effect of the amount of monomer $(\mathrm{AN})$ on the $\%$ of grafting. Reaction time: $60 \mathrm{~min}, \mathrm{H}_{2} \mathrm{O}_{2}: 0.03 \mathrm{M}$, temperature: $75^{\circ} \mathrm{C}, \mathrm{Fe} e^{+2}$ : $0.3 \mathrm{mmol}$, and $(\Delta)$ : \% of grafting.

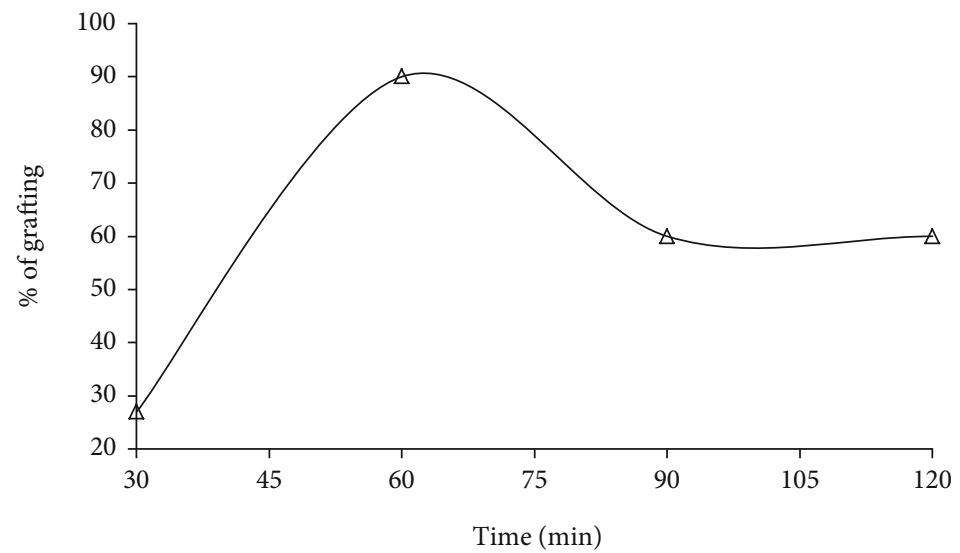

Figure 5: Effect of reaction period on the $\%$ of grafting and efficiency. $\mathrm{AN}: 8 \mathrm{ml}, \mathrm{H}_{2} \mathrm{O}_{2}: 0.03 \mathrm{M}$, temperature: $75^{\circ} \mathrm{C}, \mathrm{Fe}^{+2}: 0.3 \mathrm{mmol}$, and $(\Delta): \%$ of grafting.

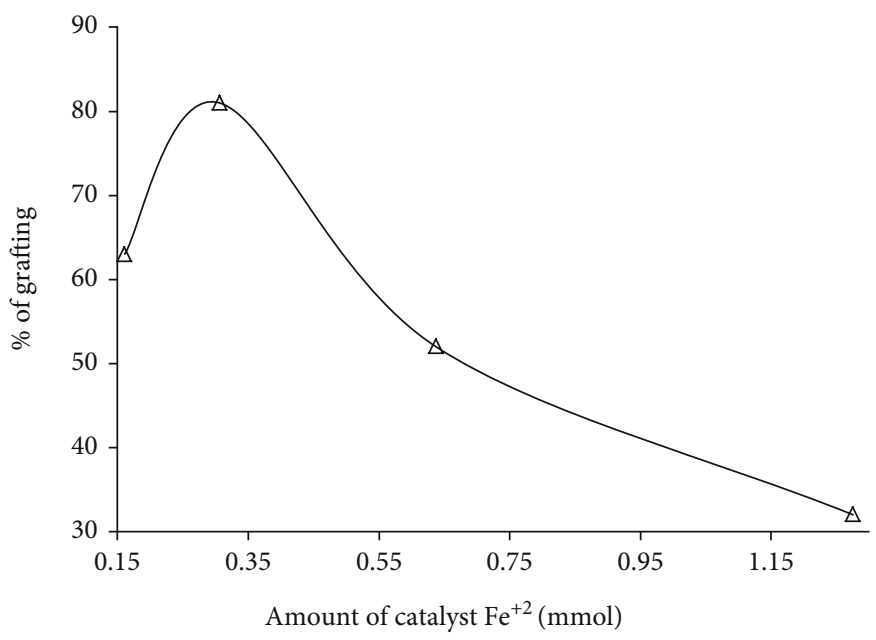

Figure 6: Effect of the amount of catalyst $\mathrm{Fe}^{+2}$ on the $\%$ of grafting. $\mathrm{AN}: 8 \mathrm{ml}, \mathrm{H}_{2} \mathrm{O}_{2}: 0.03 \mathrm{M}$, temperature: $75^{\circ} \mathrm{C}$, time: $60 \mathrm{~min}$, and $(\Delta): \%$ of grafting.

between 3000 and $3500 \mathrm{~cm}^{-1}$ were assigned to $\mathrm{O}-\mathrm{H}$ stretching vibration and bands that appeared at 2900 and $1020 \mathrm{~cm}^{-1}$ for $\mathrm{C}-\mathrm{H}$ stretching and bending modes, respectively. The charac- teristic adsorption at $2240 \mathrm{~cm}^{-1}$ for $\mathrm{C} \equiv \mathrm{N}$ stretching modes confirms the presence of acrylonitrile onto the backbone of DPWF and grafting reaction completely [41]. 


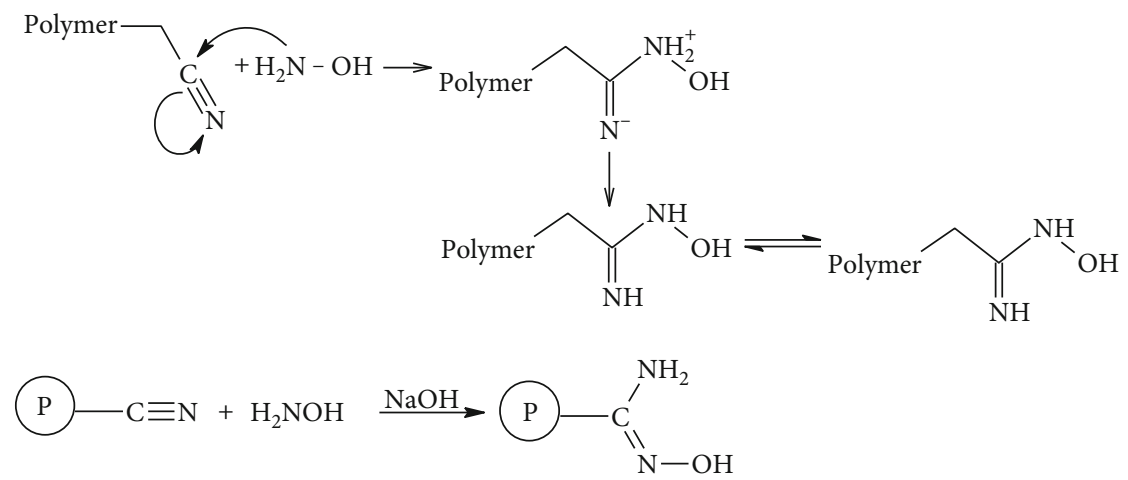

FIGURE 7: Reaction mechanism of preparation of polyamidoxime resin.

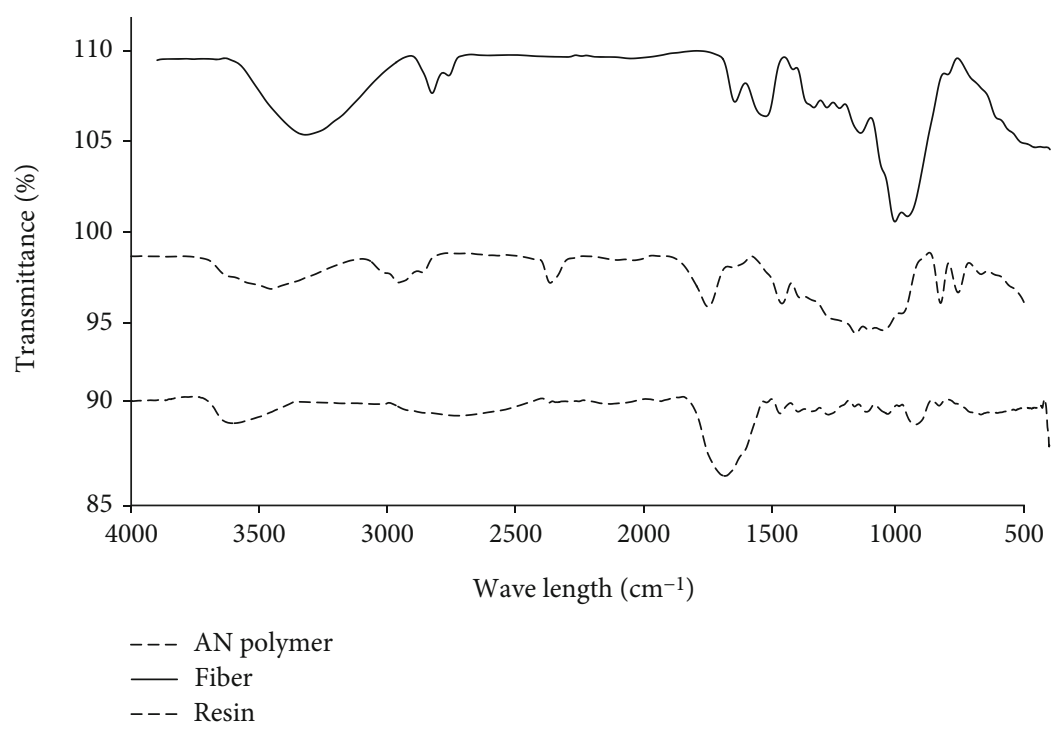

Figure 8: FTIR DPWF fiber (-), AN-g-DPWF fiber (- -), and resin containing amidoxime groups (..).

This band disappeared completely after conversion to amidoxime resin, and new adsorption band formed at $1650 \mathrm{~cm}^{-1}$ associated with $\mathrm{C}=\mathrm{N}$ vibration of the amidoxime group. Another adsorption band observed at $941 \mathrm{~cm}^{-1}$ may be assigned to the $\mathrm{N}-\mathrm{O}$ bond of the oxime group [42]. Scanning electron microscope (SEM) images were taken for DPWF before and after polymerization to investigate the changes in the morphology of the fiber surface. Figures 9 and 10 show the surface of the fiber before and after grafted polymerization, respectively. As can be seen in Figure 10, all pours on the DPWF surface were covered with polyacrylonitrile (PAN) via the chemical bond and this covering yielded a homogeneous surface with less porosity.

2.12. Effect of Initial $p H$. The $\mathrm{pH}$ solution is a substantial parameter used in the study of the removal of heavy metal ions from aqueous solution or water on account of many reasons such as its effects on the concentration of counter ions placed in adsorbent functional clusters, the level of ionization of the adsorbate during the reaction, and the solubility of metal ions. Batch technique was conducted to find out the optimum $\mathrm{pH}$ level required for the removal of heavy metals using amidoxime chelating resin. The concentration of the counter ions on the resin, ability of ionization, and solubility of adsorbates depend on $\mathrm{pH}$ [43]. A wide range of $\mathrm{pH}$ (1.0 to 6.0) was investigated to get the optimum $\mathrm{pH}$ for a fixed concentration of metals and dosage of resin at $25^{\circ} \mathrm{C}$. The adsorption of lead (II), Cr (III), and Cd (II) was maximum at the $\mathrm{pH}=5.0$ as shown in Figure 11. At low pH $(<3.0)$, the competition between $\mathrm{H}^{+}$ions for the resin sites increased and the resin's chelating ability was greatly reduced. At $\mathrm{pH} 5$, the competition of $\mathrm{H}^{+}$ions for the resin sites decreases and the chelating ability of the metal ion increases [44]. Equation (2) is used to calculate the percentage of the removal of metal ions using this resin $[39,45,46]$.

$$
\text { \%of removal }=\frac{C_{0}-C_{e}}{\mathrm{C}_{0}} \times 100 .
$$

2.13. Effect of Contact Time and Initial Concentration. The contact time is one of the important parameters to study as it affects the adsorption of heavy metals onto chelating resin. From Figure 12, it can be observed that the adsorption of heavy metals increases with the increase in the contact time. Also, the adsorption was fast in the beginning until it reaches equilibrium at $35 \mathrm{~min}$, and afterwards, the value of $q_{t}(\mathrm{mg} / \mathrm{g})$ 


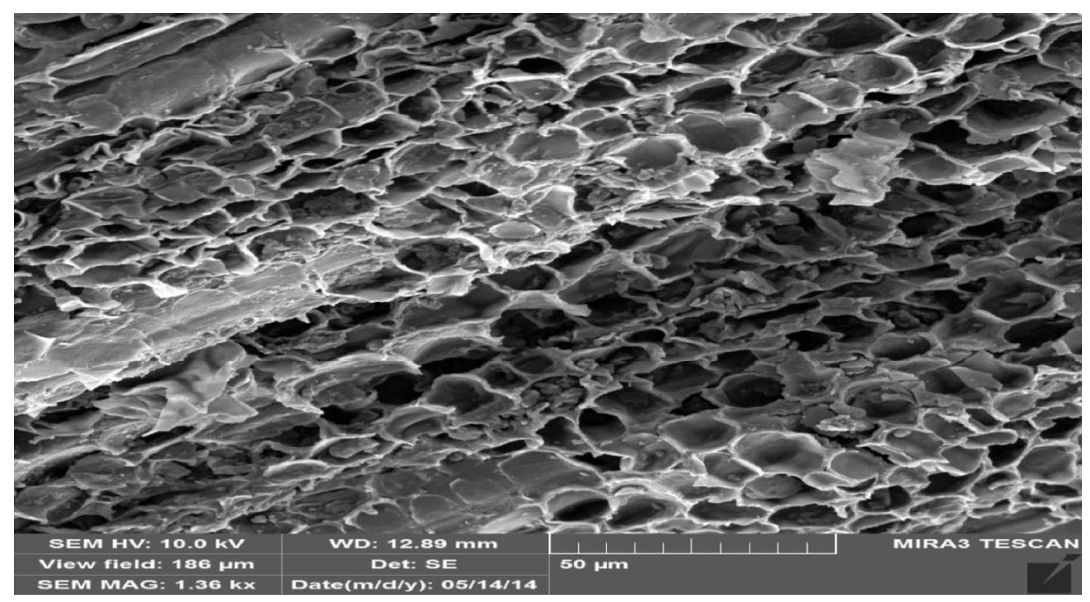

FIGURE 9: Scanning electron micrographs of DPWF before grafting, SEM MAG (1.36 KX).

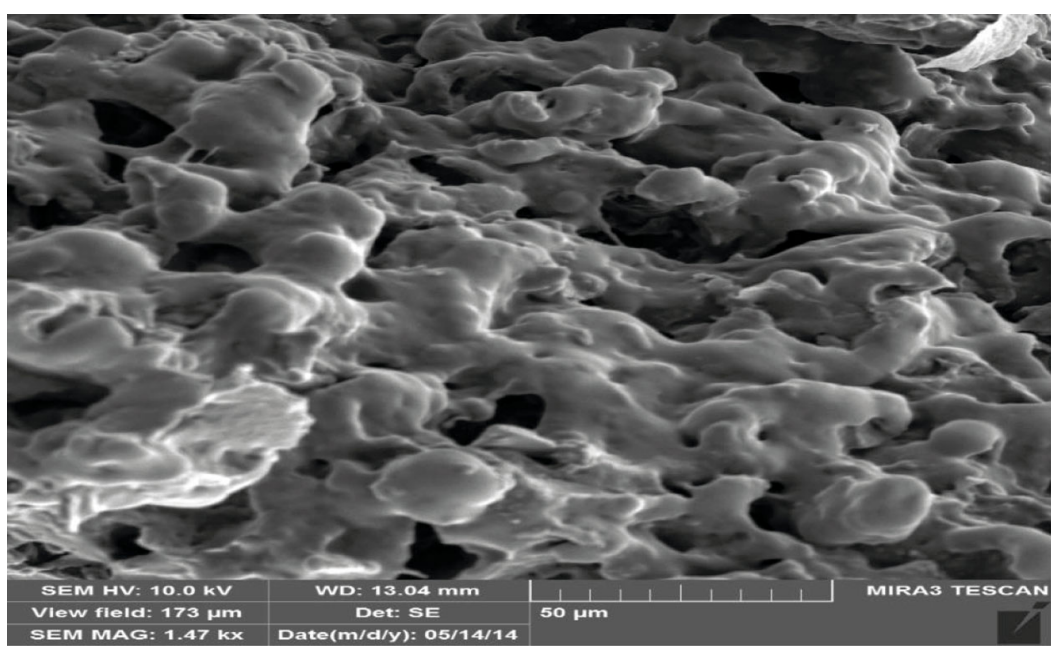

FIGURE 10: Scanning electron micrographs of DPWF after grafting, SEM MAG (1.47 KX).

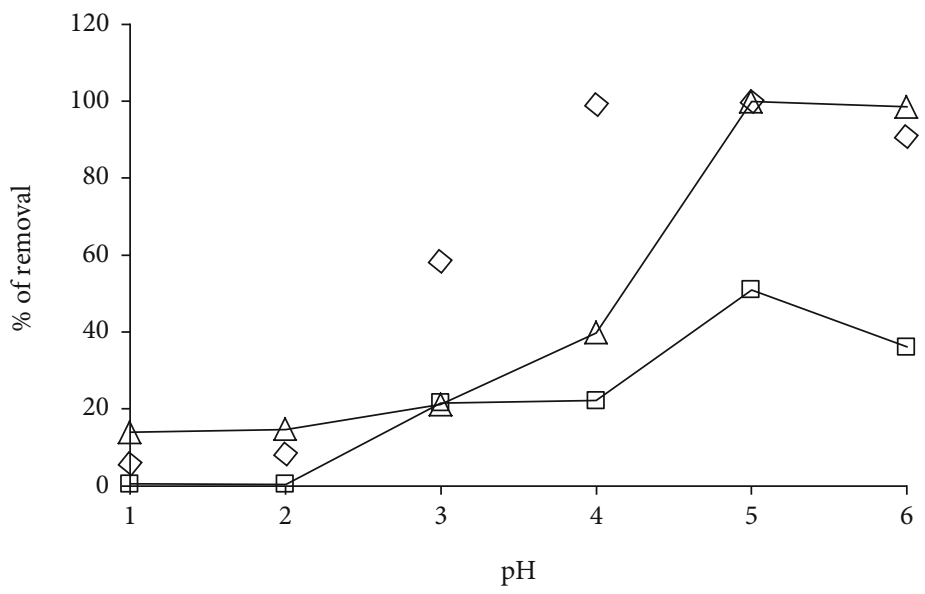

$\diamond \%$ of removal $\mathrm{Pb}$

$\square \%$ of removal Cd

FIGURE 11: Effect of $\mathrm{pH}$ on the adsorption of $\left(\mathrm{Pb}^{+2}\right),\left(\mathrm{Cr}^{+3}\right)$, and $\left(\mathrm{Cd}^{+2}\right)$ ions; dosage of chelating resin: 1 g; ion concentration: $50 \mathrm{mg} / \mathrm{L}$; time: $60 \mathrm{~min}$; and temperature: $25^{\circ} \mathrm{C}$. 


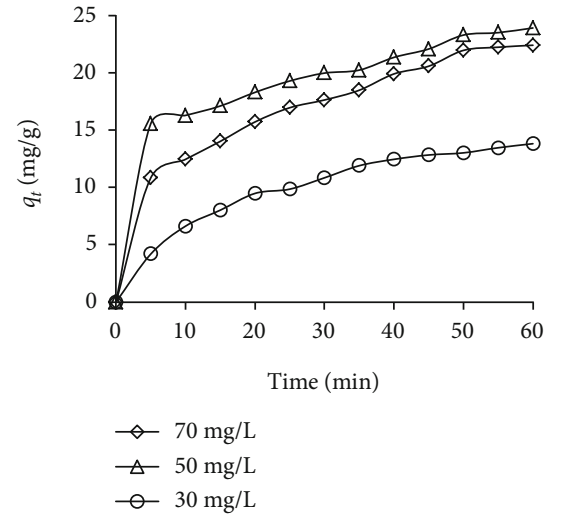

(a)

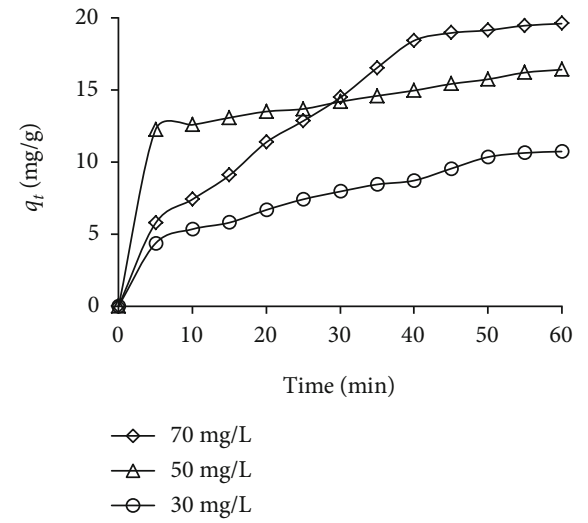

(b)

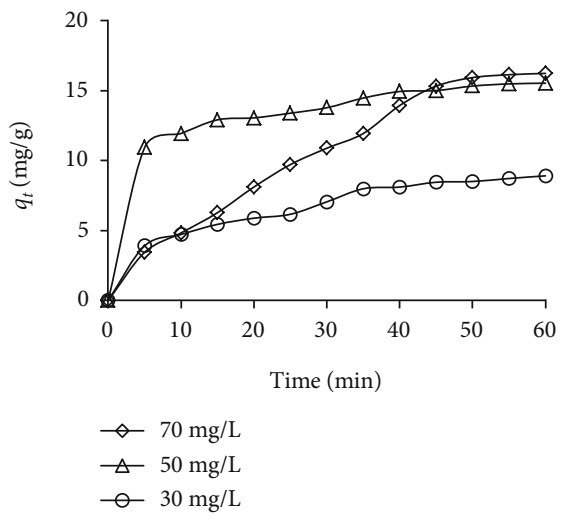

(c)

FIGURE 12: Effect of contact time on (a) lead (II), (b) Cr (III), and (c) Cd (II) adsorption at different initial feed concentration; solution: pH 5; and temperature: $25^{\circ} \mathrm{C}$.

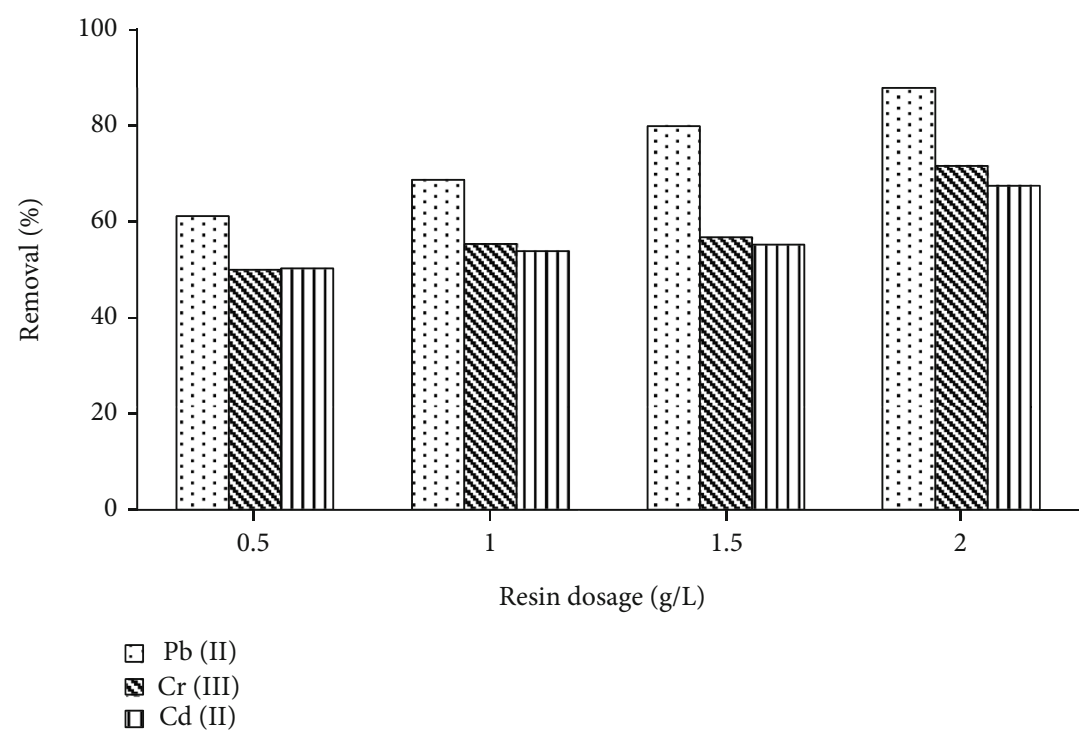

Figure 13: Effect of adsorbent dosage on adsorption of lead (II), Cr (III), and Cd (II); initial concentrations: $50 \mathrm{mg} / \mathrm{L}$; time: $60 \mathrm{~min}$; solution: $\mathrm{pH} 5$; and temperature: $25^{\circ} \mathrm{C}$.

remains constant. This can be attributed to the availability of active sites on the surface of chelating resin in the beginning of reaction [47]. Initial concentration of metals under study: lead (II), Cr (III), and Cd (II), influenced the removal of these metals. The amount of metal ions, $q_{t}$ (milligrams per gram) adsorbed, is calculated by increasing the initial concentrations. The following equation is used to calculate metal ion adsorption at certain time, $t\left(q_{t} \mathrm{mg} / \mathrm{g}\right)$ :

$$
q_{t}=\left(c_{0}-c_{t}\right) \times \frac{v}{m} .
$$

This can be illustrated by the ratio between available surface and initial metal ion concentration. On higher concentration, this ratio was low and it increased with the lower concentration and the initial concentration also affects the removal of heavy metals [48].
2.14. Effect of Adsorbent Dosage. The efficiency of the amidoxime chelating resin dosage was investigated on the basis of its initial concentrations. Adsorption of lead (II), Cr (III), and Cd (II) was studied with different dosages of resin and $50 \mathrm{mg} / \mathrm{l}$ as the initial concentration of metals at $25^{\circ} \mathrm{C}$ and $\mathrm{pH}=5$. According to Figure 13, when the resin dosage was increased from $0.05 \mathrm{~g} / \mathrm{l}$ to $2 \mathrm{~g} / \mathrm{l}$, the percentage of removal from $61.1 \%$ to $87.84 \%$ for lead (II), from 49.94 to $71.50 \%$ for chromium (III), and from 50.26 to 67.48 for cadmium (II) was observed. This increase in the removal percentage can be attributed to the availability of huge surface area and number of active sites on account of increase in the dosage of resin at constant concentration of metal ions.

2.15. Adsorption Kinetics. To investigate the adsorption mechanism and reaction pathways, some adsorption kinetic studies were conducted. Various kinetic models were applied to analyse the adsorption process of lead (II), $\mathrm{Cr}$ (III), and Cd 


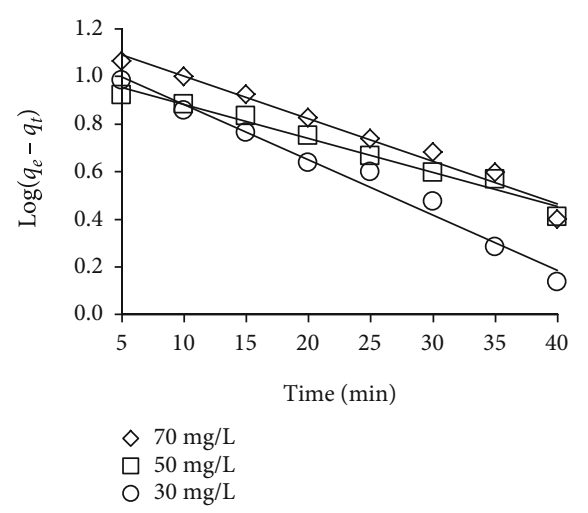

(a)

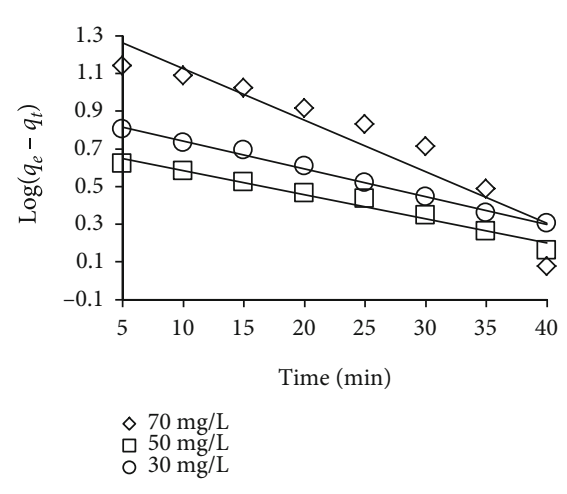

(b)

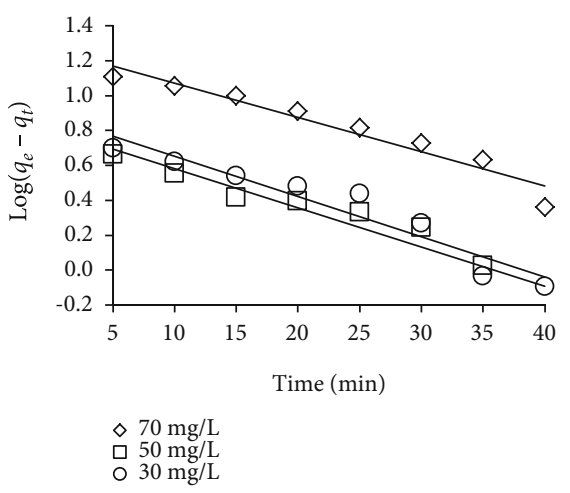

(c)

Figure 14: Lagergren first-order plot for adsorption of (a) $\mathrm{Pb}$ (II), (b) $\mathrm{Cr}$ (III), and (c) Cd (II) on amidoxime chelating resin for different initial feed concentrations at $\mathrm{pH} 5$ and temperature at $25^{\circ} \mathrm{C}$.

(II) onto chelating resin. These models include pseudo-firstorder, pseudo-second-order, and intraparticle diffusion. Models with high correlation coefficients $\left(R^{2}\right)$ may describe the adsorption of metal onto chelating resin.

2.15.1. The Pseudo-First-Order Model. The pseudo-firstorder kinetic model illustrates the adsorption mechanisms in solid-liquid systems, which is generally expressed as

$$
\log \left(q_{e}-q_{t}\right)=\log q_{e}-\frac{k_{1} t}{2.303}
$$

where $k_{1}$ is the rate constant of pseudo-first-order adsorption (per minute) and $q_{t}$ and $q_{e}$ are the quantities of metal ions adsorbed (milligrams per gram) at time $t$ and equilibrium, respectively $[39,49]$. The plots of $\log \left(q_{e}-q_{t}\right)$ versus $t$ demonstrated in Figure 14 give the value rate constant $k_{1}$ and adsorption density $q_{e}$ from the slope and intercept, respectively. Bad linearity was obtained for this model, and it was clear from the values of correlation coefficients $\left(R^{2}\right)$ which was low for different concentrations. Moreover, no agreement was observed between the experimentally observed equilibrium adsorption ( $q_{e}$, exp) and that derived theoretically $\left(q_{e}, \mathrm{cal}\right)$, which means that the adsorption of metal ions onto chelating resin kinetic data was not compatible with the pseudo-first-order kinetic model.

2.15.2. The Pseudo-Second-Order Equation. The pseudosecond-order adsorption kinetic rate is expressed as

$$
\frac{d q_{t}}{d t}=k_{2}\left(q_{e}-q_{t}\right)^{2}
$$

where $k_{2}$ is the rate constant of the pseudo-second-order sorption (g/mg.min), $q_{e}$ and $q_{t}$ are the sorption capacities at equilibrium and time $t(\mathrm{mg} / \mathrm{g})$, respectively. For the boundary conditions $t=0$ to $t=t$ and $q_{t}=0$ to $q_{t}=q_{t}$, the integrated form of Equation (5) will be as

$$
\frac{1}{q_{e}-q_{t}}=\frac{1}{q_{e}}+k_{2} t .
$$

Equation (6) can be expressed as

$$
\frac{t}{q_{t}}=\frac{1}{k_{2} q_{e^{2}}}+\frac{t}{q_{e}} .
$$

The initial adsorption rate, $h$ (milligrams per gram per minute), is given as

$$
h=k_{2 q e^{2}} .
$$

Equation (7) also can be written as

$$
\frac{t}{q_{t}}=\frac{1}{h}+\frac{t}{q_{e}} .
$$

The plots of $t / q_{t}$ versus $t$ from Equation (9) at different concentrations of lead (II), Cr (III), and Cd (II) are shown in Figure 15. From slope and intercept, adsorption parameters $q_{e}$ (Cal.) and $k_{2}$ were calculated, respectively (Table 1 ). The high linearity of the plots was indicated by values of correlation coefficients $\left(R^{2}\right)(\geq 0.99)$, which means that the adsorption kinetics between amidoxime chelating resin and heavy metals can be described using a pseudo-second-order adsorption kinetic model. Moreover, the good agreement between $\left(q_{e}\right.$, Cal. $)$ and ( $q_{e}$, Exp.) gives evidence for the compatibility of the adsorption data. This shows that the adsorption of heavy metals onto amidoxime chelating resin occurs through the chemical interaction between the adsorbent and adsorbate [50-52].

2.15.3. The Intraparticle Diffusion Model. Adsorption mechanism and intraparticle diffusion rate determined steps of lead (II). Cr (III) and Cd (II) onto chelating resin were identified using the Weber and Morris model. The rate constant for intraparticle $\left(\mathrm{k}_{\mathrm{id}}\right)$ can be expressed as

$$
q_{t}=k_{\mathrm{id}} t^{1 / 2}+\mathrm{C}
$$

Figure 16 shows the plots of $q_{t}$ versus $t^{1 / 2}$. It is clear that all lines for different concentrations do not pass through the 


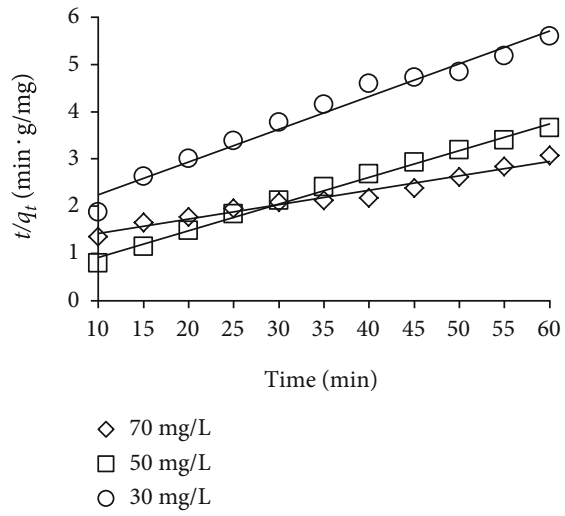

(a)

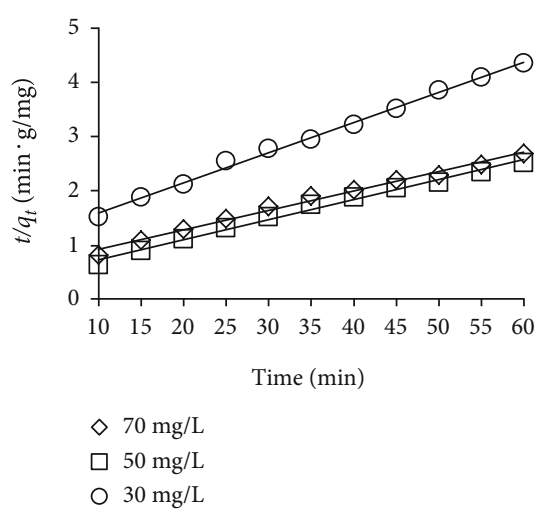

(b)

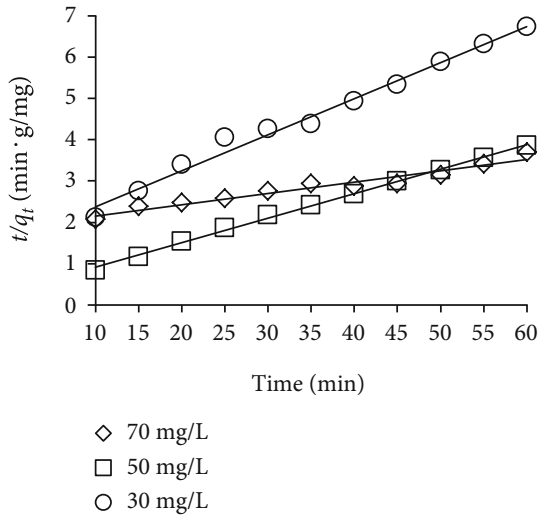

(c)

Figure 15: Pseudo-second-order kinetic plot for adsorption of (a) Pb (II), (b) Cr (III), and (c) Cd (II) on amidoxime chelating resin for different initial feed concentrations at $\mathrm{pH} 5$ and temperature at $25^{\circ} \mathrm{C}$.

TABLE 1: Kinetic constant parameters obtained for heavy metal adsorption on polyamidoxime resin.

\begin{tabular}{|c|c|c|c|c|c|c|c|c|c|c|c|c|}
\hline \multirow[b]{2}{*}{ Metal } & \multicolumn{6}{|c|}{ Pseudo-first order } & \multicolumn{3}{|c|}{ Pseudo-second order } & \multicolumn{3}{|c|}{ Intraparticle diffusion model } \\
\hline & $\begin{array}{c}C_{i} \\
(\mathrm{mg} / \mathrm{L})\end{array}$ & $\begin{array}{l}q_{e} \exp \\
(\mathrm{mg} / \mathrm{g})\end{array}$ & $\begin{array}{c}K_{1}\left(10^{-3}\right) \\
\left(\min ^{-1}\right)\end{array}$ & $\begin{array}{c}q_{e} \mathrm{cal} \\
(\mathrm{mg} / \mathrm{g})\end{array}$ & $R^{2}$ & $\begin{array}{c}K_{2}\left(10^{-2}\right) \\
(\mathrm{g} / \mathrm{mg} \cdot \mathrm{min})\end{array}$ & $\begin{array}{c}q_{e} \mathrm{cal} \\
(\mathrm{mg} / \mathrm{g})\end{array}$ & $\begin{array}{c}h \\
(\mathrm{~g} / \mathrm{min})\end{array}$ & $R^{2}$ & $\begin{array}{c}K_{\mathrm{id}} \\
(\mathrm{mg} / \mathrm{g} \cdot \mathrm{min})\end{array}$ & $\begin{array}{c}C \\
(\mathrm{mg} / \mathrm{g})\end{array}$ & $R^{2}$ \\
\hline \multirow{3}{*}{ Lead (II) } & 70 & 22.40 & 41.22 & 518.8 & 0.976 & 0.30 & 17.95 & 0.97 & 0.996 & 2.262 & 5.397 & 0.992 \\
\hline & 50 & 23.90 & 32.7 & 226.01 & 0.976 & 0.40 & 27.03 & 2.91 & 0.992 & 1.733 & 10.521 & 0.990 \\
\hline & 30 & 13.81 & 53.19 & 363.09 & 0.981 & 0.24 & 27.85 & 1.82 & 0.990 & 1.567 & 2.112 & 0.979 \\
\hline \multirow{3}{*}{ Chromium (III) } & 70 & 19.58 & 62.87 & 1659.7 & 0.880 & 0.08 & 32.79 & 0.898 & 0.974 & 2.929 & 1.631 & 0.965 \\
\hline & 50 & 16.39 & 33.85 & 111.88 & 0.994 & 0.93 & 17.64 & 2.89 & 0.995 & 0.856 & 9.645 & 0.986 \\
\hline & 30 & 10.72 & 29.48 & 43.58 & 0.974 & 0.31 & 14.47 & 0.64 & 0.970 & 1.259 & 1.08 & 0.988 \\
\hline \multirow{3}{*}{ Cadmium (II) } & 70 & 16.24 & 45.14 & 832.6 & 0.937 & 0.399 & 36.49 & 0.53 & 0.947 & 2.745 & 3.999 & 0.983 \\
\hline & 50 & 15.54 & 53.19 & 19.13 & 0.921 & 1.1 & 16.86 & 3.14 & 0.998 & 0.808 & 9.54 & 0.977 \\
\hline & 30 & 8.92 & 51.82 & 72.31 & 0.924 & 0.503 & 11.48 & 0.66 & 0.986 & 0.977 & 1.662 & 0.967 \\
\hline
\end{tabular}

point of origin indicating the difficulty of predicting the mechanism of the overall process, and it seems to be very complex $[46,53]$.

2.16. Adsorption Isotherm Models. The adsorption efficiency of polyamidoxime chelating resin towards heavy metals was tested using some isotherm models. It describes the partition of adsorbate molecules between liquid and solid phases at equilibrium. Langmuir and Freundlich adsorption isotherm models were used to determine the adsorption capacity of amidoxime chelating resin towards lead (II), Cr (III), and Cd (II).

2.16.1. The Langmuir Isotherm Model. The Langmuir model assumes that the monolayer adsorption process takes place between the adsorbate and adsorbent, and the surface is homogenous with a finite number of active sites when sites are filled with adsorbate molecules. There is no chance of further adsorption on this site, and the saturation point is accomplished [54]. The linear equation is expressed as

$$
\frac{C_{e}}{q_{e}}=\frac{1}{K_{L} q_{m}}+\frac{C_{e}}{q_{m}},
$$

where $C_{e}$ is the equilibrium concentration ( $\left.\mathrm{mg} / \mathrm{l}\right)$ of metals in solution; $q_{e}$ is the amount of metal ions adsorbed $(\mathrm{mg} / \mathrm{g})$ at equilibrium; $K_{L}$ is the Langmuir equilibrium constant $(1 / \mathrm{mg})$, and it is related to the affinity of adsorption sites; and $q_{m}$ gives the maximum theoretical monolayer adsorption capacity (mg/g). The values of $q_{m}$ and $K_{L}$ (Table 2) were obtained from the slope and intercept, respectively, of plots of $C_{e} / q_{e}$ versus $C_{e}$, which are shown in Figure 17 . The linearity and high values of correlation coefficients $\left(R^{2}\right)$ indicate that the Langmuir model describes the adsorption process very well, confirming the formation of monolayer. Weber and Chakravorti [55] defined the separation factor $\left(R_{L}\right)$ as a characteristic dimensionless equilibrium parameter for the Langmuir model, and it is expressed as

$$
R_{L}=\frac{1}{1+K_{L} C_{o}}
$$

The values of $R_{L}$ for each initial concentration was less than unity and greater than zero indicating the favourable adsorption of lead (II), Cr (III), and Cd (II) on polyamidoxime chelating resin [53]. 


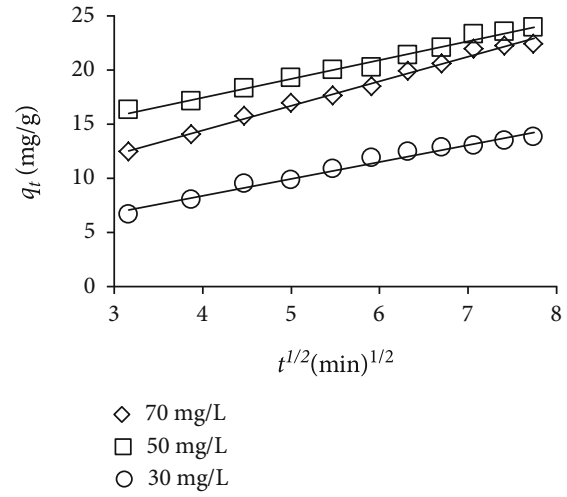

(a)

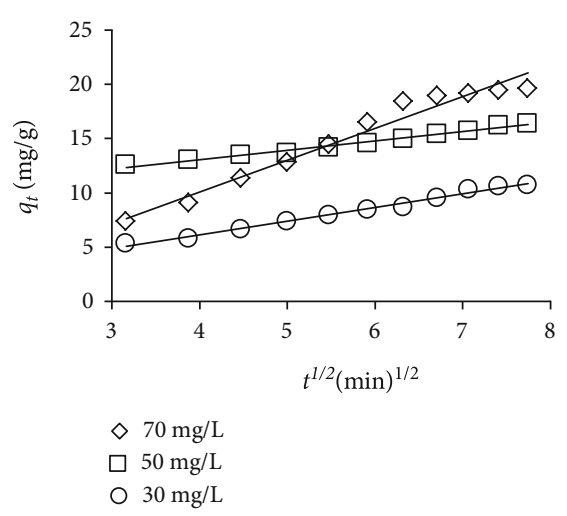

(b)

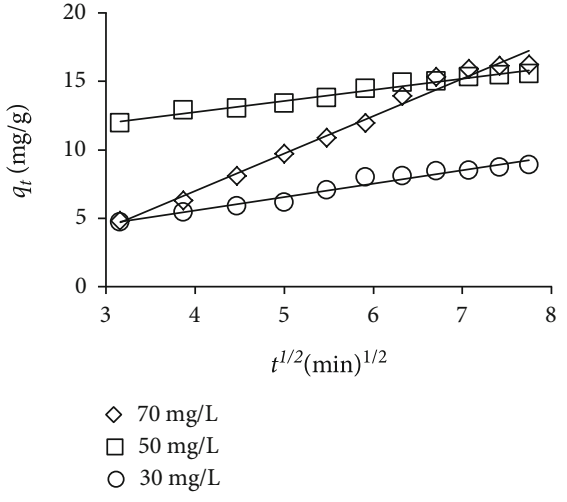

(c)

FIGURE 16: Intraparticle diffusion kinetic plot for adsorption of (a) $\mathrm{Pb}$ (II), (b) Cr (III), and (c) Cd (II) on amidoxime chelating resin for different initial feed concentrations at $\mathrm{pH} 5$ and temperature at $25^{\circ} \mathrm{C}$.

TABle 2: Langmuir and Freundlich isotherm constants for lead (II), Cr (III), and Cd (II) adsorption on amidoxime chelating resin.

\begin{tabular}{lccccccrrr}
\hline \multirow{2}{*}{ Compounds } & \multirow{2}{*}{$T(\mathrm{k})$} & \multicolumn{3}{c}{ Langmuir isotherm constants } & \multicolumn{3}{c}{ Freundlich isotherm constants } \\
& & $q_{m}(\mathrm{mg} / \mathrm{g})$ & $K_{L}(\mathrm{~L} / \mathrm{mg})$ & $R_{L}$ & $R^{2}$ & $1 / n$ & $n$ & $K_{F}$ & $R^{2}$ \\
\hline Lead (II) & 298.16 & 43.86 & 9.12 & 0.002 & 0.999 & 0.04 & 23.15 & 48.62 & 0.8638 \\
Chromium (III) & 298.16 & 42.74 & 5.32 & 0.004 & 0.999 & 0.06 & 15.43 & 49.74 & 0.9701 \\
Cadmium (II) & 298.16 & 32.47 & 1.54 & 0.012 & 0.993 & 0.10 & 10.04 & 48.07 & 0.7647 \\
\hline
\end{tabular}

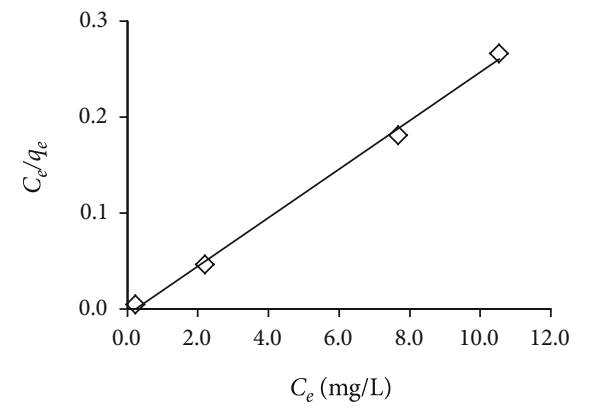

(a)

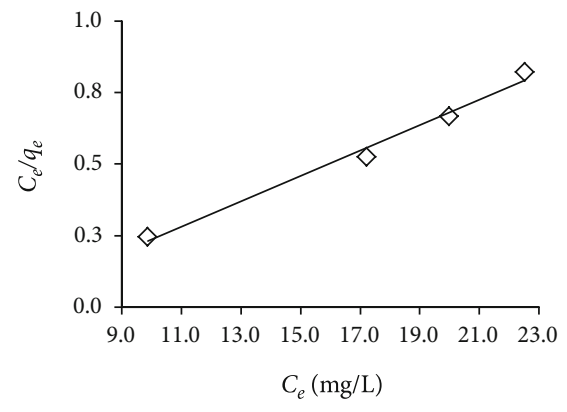

(b)

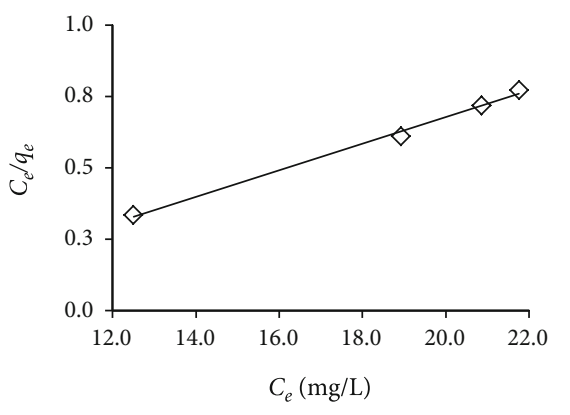

(c)

FIGURE 17: Langmuir adsorption isotherms for adsorption of (a) $\mathrm{Pb}$ (II), (b) $\mathrm{Cr}$ (III), and (c) Cd (II) on amidoxime chelating resin, pH 5, and temperature at $25^{\circ} \mathrm{C}$.

2.16.2. The Freundlich Isotherm Model. The Freundlich model is always used to describe the adsorption on heterogeneous surface of adsorbent [56]. Different initial concentrations of heavy metals were used with fixed dosage of amidoxime resin to obtain the equilibrium data. The Freundlich isotherm model is expressed as follows:

$$
\ln q_{e}=\ln k_{f}+\frac{1}{n} \ln C_{e}
$$

where $K_{f}(\mathrm{mg} / \mathrm{g})$ and $n(\mathrm{~g} / \mathrm{L})$ are the Freundlich adsorption constants. The plots of $\ln q_{e}$ against $\ln C_{e}$ shown in Figure 18 give straight lines. From the slope and intercept of those lines, the values of $n$ and $K_{f}$ can be calculated. Bad linearity and low values of correlation coefficient $\left(R^{2}\right)$ indicate disagreement between equilibrium data and this model.
Values of $n$ more than the unit mean favourable adsorption condition, and lead (II), Cr (III), and Cd (II) are favourably adsorbed via amidoxime resin [53].

\section{Conclusion}

This study used the grafted copolymerization of date palm wood fiber using hydrogen peroxide as an initiator and ammonium ferrous sulphate as a catalyst. It studied the grafting parameters for obtaining the best grafting percentage. The grafting percentage depends upon the parameters such as the reaction period, reaction temperature, amount of the catalyst, concentration of the initiator, and monomer volume. The best grafting percent was obtained using acrylonitrile monomer under following conditions: $8 \mathrm{ml}$ monomer, $0.03 \mathrm{M}$ solution of hydrogen peroxide, and 


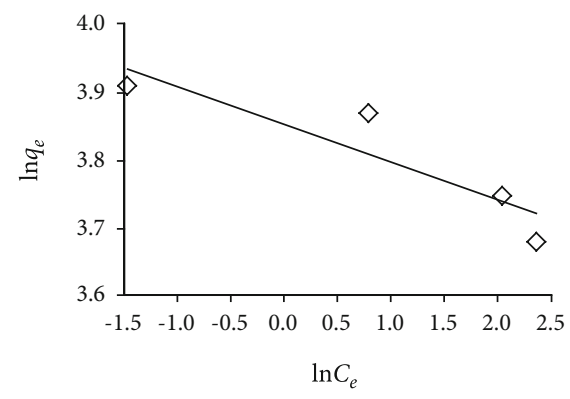

(a)

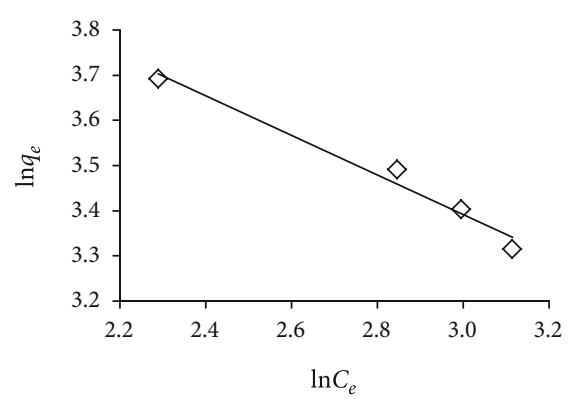

(b)

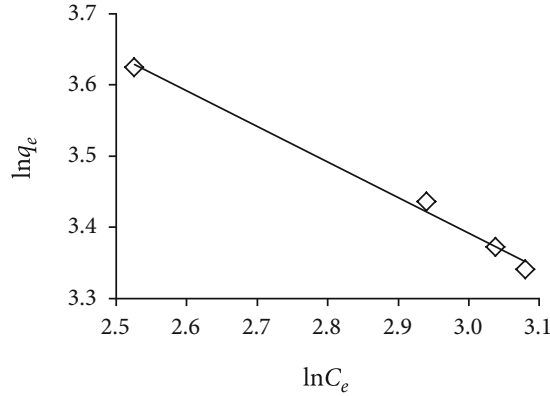

(c)

FIGURE 18: Freundlich adsorption isotherms for adsorption of (a) $\mathrm{Pb}$ (II), (b) $\mathrm{Cr}$ (III), and (c) $\mathrm{Cd}$ (II) on amidoxime chelating resin, pH 5, and temperature at $25^{\circ} \mathrm{C}$.

$0.306 \mathrm{mmol}$ concentration of the catalyst. The reaction completed in $60 \mathrm{~min}$ at $75^{\circ} \mathrm{C}$.

FTIR and STEM techniques were used for grafting products. Hydroxylamine was used for treating an AN-grafted copolymer for producing polyamidoxime chelating resins. The conversion process was confirmed using the FT-IR technique. Also, the batch template was used for examining the absorption capacity for heavy metal ions. The absorption $\mathrm{pH}$ value was found to range between 5 and 6 . The better absorption behavior was observed for cadmium (II), chromium (III), and lead (II). The Langmuir isotherm found the correlation coefficient for resin to be 0.99 , which was better than Freundlich isotherms.

\section{Data Availability}

The figures and results data used to support the findings of this study are included within the article.

\section{Conflicts of Interest}

The author declares no conflict of interest.

\section{Acknowledgments}

The author would like to acknowledge the support provided by King Abdulaziz City for Science and Technology (KACST) through the Science and Technology Unit at King Fahd University of Petroleum and Minerals (KFUPM) for funding this work through project No. 11-WAT2170-04 as part of the National Science, Technology and Innovation Plan. I would like to acknowledge the thesis of Nadir Mohammed Adam Osman whose extension was presented in this research from the thesis titled as "Removal of Some Heavy Metals Using Resins Prepared by Free Radical Polymerization of Grafted Date-Palm-Wood Copolymer with Different Vinyl Monomers" presented at King Fahd University of Petroleum \& Minerals, Dhahran, Saudi Arabia.

\section{References}

[1] W. Ghori, N. Saba, M. Jawaid, and M. Asim, "A review on date palm (phoenix dactylifera) fibers and its polymer composites,"
IOP Conference Series: Materials Science and Engineering, vol. 368, no. 1, article 012009, 2019.

[2] D. Purkayastha, U. Mishra, and S. Biswas, "A comprehensive review on Cd (II) removal from aqueous solution," Journal of Water Process Engineering, vol. 2, pp. 105-128, 2014.

[3] E. Bernard, A. Jimoh, and J. Odigure, "Heavy metals removal from industrial wastewater by activated carbon prepared from coconut shell," Research Journal of Chemical Sciences, vol. 2231, article 606X, 2013.

[4] F. Fu and Q. Wang, "Removal of heavy metal ions from wastewaters: a review," Journal of Environmental Management, vol. 92, no. 3, pp. 407-418, 2011.

[5] H. Bessbousse, J.-F. Verchère, and L. Lebrun, "Characterisation of metal-complexing membranes prepared by the semi-interpenetrating polymer networks technique. Application to the removal of heavy metal ions from aqueous solutions," Chemical Engineering Journal, vol. 187, pp. 16-28, 2012.

[6] M. K. Thakur, K. T. Vijay, K. G. Raju, and P. Asokan, "Synthesis and applications of biodegradable soy based graft copolymers: a review," ACS Sustainable Chemistry \& Engineering, vol. 4, no. 1, pp. 1-17, 2015.

[7] V. K. Thakur, M. K. Thakur, and R. K. Gupta, "Synthesis of lignocellulosic polymer with improved chemical resistance through free radical polymerization," International Journal of Biological Macromolecules, vol. 61, pp. 121126, 2013.

[8] T. A. Khan and V. S. Ved, "Removal of cadmium (II), lead (II), and chromium (VI) ions from aqueous solution using clay," Toxicological \& Environ Chemistry, vol. 92, no. 8, pp. 14351446, 2010.

[9] M. T. Amin, A. A. Alazba, and U. Manzoor, "A review of removal of pollutants from water/wastewater using different types of nanomaterials," Advances in Materials Science and Engineering, vol. 2014, 24 pages, 2014.

[10] S. L. R. K. Kanamarlapudi, K. C. Vinay, and M. Sudhamani, "Application of biosorption for removal of heavy metals from wastewater," in Biosorption, J. Derco and B. Vrana, Eds., vol. 18, p. 69, IntechOpen, 2018.

[11] N. Ünlü and E. Mustafa, "Removal of heavy metal ions by using dithiocarbamated-sporopollenin," Separation and Purification Technology, vol. 52, no. 3, pp. 461-469, 2007.

[12] X. Yuan, B. Zhu, G. Tong, Y. Su, and X. Zhu, "Wet-chemical synthesis of Mg-doped hydroxyapatite nanoparticles by step reaction and ion exchange processes," Journal of Materials Chemistry B, vol. 1, no. 47, pp. 6551-6559, 2013. 
[13] M. H. Gheith, M. A. Aziz, W. Ghori et al., "Flexural, thermal and dynamic mechanical properties of date palm fibres reinforced epoxy composites," Journal of Materials Research and Technology, vol. 8, no. 1, pp. 853-860, 2019.

[14] N. Rahman, M. S. Hossen, A. R. Miah et al., "Removal of $\mathrm{Cu}$ (II), $\mathrm{Pb}$ (II) and $\mathrm{Cr}$ (VI) ions from aqueous solution using amidoximated non-woven polyethylene-g-acrylonitrile fabric," Journal of Environmental Health Science and Engineering, vol. 17, no. 1, pp. 183-194, 2019.

[15] K. Z. Elwakeel, A. A. el-Bindary, E. Y. Kouta, and E. Guibal, "Functionalization of polyacrylonitrile/Na-Y-zeolite composite with amidoxime groups for the sorption of $\mathrm{Cu}$ (II), Cd (II) and $\mathrm{Pb}$ (II) metal ions," Chemical Engineering Journal, vol. 332, pp. 727-736, 2018.

[16] X. Jin, Z. Xiang, Q. Liu, Y. Chen, and F. Lu, "Polyethyleneimine-bacterial cellulose bioadsorbent for effective removal of copper and lead ions from aqueous solution," Bioresource Technology, vol. 244, pp. 844-849, 2017.

[17] Lalita, A. P. Singh, and R. K. Sharma, "Synthesis and characterization of graft copolymers of chitosan with NIPAM and binary monomers for removal of $\mathrm{Cr}$ (VI), Cu (II) and Fe (II) metal ions from aqueous solutions," International journal of biological macromolecules, vol. 99, pp. 409-426, 2017.

[18] H. Helten, "Doping the backbone of $\pi$-conjugated polymers with tricoordinate boron: synthetic strategies and emerging applications," Chemistry-An Asian Journal, vol. 14, no. 7, pp. 919-935, 2019.

[19] L. Gao, C. Li, W. Huang et al., "MXene/polymer membranes: synthesis, properties, and emerging applications," Chemistry of Materials, vol. 32, no. 5, pp. 1703-1747, 2020.

[20] M. Jonoobi, M. shafie, Y. Shirmohammadli, A. Ashori, H. Zarea-Hosseinabadi, and T. Mekonnen, "A review on date palm tree: properties, characterization and its potential applications," Journal of Renewable Materials, vol. 7, no. 11, pp. 1055-1075, 2019.

[21] T. Ahmad, M. Danish, M. Rafatullah et al., "The use of date palm as a potential adsorbent for wastewater treatment: a review," Environmental Science and Pollution Research, vol. 19, no. 5, pp. 1464-1484, 2012.

[22] K. Al-Kaabi, A. Al-Khanbashi, and A. Hammami, "Date palm fibers as polymeric matrix reinforcement: DPF/polyester composite properties," Polymer Composites, vol. 26, no. 5, pp. 604613, 2005.

[23] I. L. El-Juhany, "Degradation of date palm trees and date production in Arab countries: causes and potential rehabilitation," Australian Journal of Basic and Applied Sciences, vol. 4, no. 8, pp. 3998-4010, 2010.

[24] A.-N. A. El-Hendawy, "The role of surface chemistry and solution $\mathrm{pH}$ on the removal of $\mathrm{Pb}^{2+}$ and $\mathrm{Cd}^{2+}$ ions via effective adsorbents from low-cost biomass," Journal of hazardous materials, vol. 167, no. 1-3, pp. 260-267, 2009.

[25] A. el Nemr, A. Khaled, O. Abdelwahab, and A. el-Sikaily, "Treatment of wastewater containing toxic chromium using new activated carbon developed from date palm seed," Journal of Hazardous Materials, vol. 152, no. 1, pp. 263275, 2008.

[26] F. Bouhamed, Z. Elouear, and J. Bouzid, “Adsorptive removal of copper (II) from aqueous solutions on activated carbon prepared from Tunisian date stones: equilibrium, kinetics and thermodynamics," Journal of the Taiwan Institute of Chemical Engineers, vol. 43, no. 5, pp. 741-749, 2012.
[27] Z. Belala, M. Jeguirim, M. Belhachemi, F. Addoun, and G. Trouvé, "Biosorption of copper from aqueous solutions by date stones and palm-trees waste," Environmental Chemistry Letters, vol. 9, no. 1, pp. 65-69, 2011.

[28] N. M. Hilal, I. A. Ahmed, and R. E. el-Sayed, "Activated and nonactivated date pits adsorbents for the removal of copper(II) and cadmium(II) from aqueous solutions," ISRN Physical Chemistry, vol. 2012, 11 pages, 2012.

[29] M. Abdulkarim and F. A. Al-Rub, "Adsorption of lead ions from aqueous solution onto activated carbon and chemicallymodified activated carbon prepared from date pits," Adsorption Science \& Technology, vol. 22, no. 2, pp. 119-134, 2016.

[30] S. K. Yadav, S. Sinha, and D. K. Singh, "Chromium (VI) removal from aqueous solution and industrial wastewater by modified date palm trunk," Environmental Progress \& Sustainable Energy, vol. 34, no. 2, pp. 452-460, 2015.

[31] E.-S. I. el-Shafey and S. M. Z. al-Kindy, "Removal of $\mathrm{Cu}^{2+}$ and $\mathrm{Ag}^{+}$from aqueous solution on a chemically-carbonized sorbent from date palm leaflets," Environmental Technology, vol. 34, no. 3, pp. 395-406, 2013.

[32] F. Banat, S. Al-Asheh, and D. Al-Rousan, "A comparative study of copper and zinc ion adsorption on to activated and non-activated date-pits," Adsorption Science \& Technology, vol. 20, no. 4, pp. 319-335, 2016.

[33] N. A. Ibrahim, W. M. Z. W. Yunus, F. A. Abu-Ilaiwi, M. Z. A. Rahman, M. Bin Ahmad, and K. Z. M. Dahlan, "Graft copolymerization of methyl methacrylate onto oil palm empty fruit bunch fiber using $\mathrm{H}_{2} \mathrm{O}_{2} / \mathrm{Fe}^{2+}$ as an initiator," Journal of Applied Polymer Science, vol. 89, no. 8, pp. 2233-2238, 2003.

[34] F. A. Abu-Ilaiwi, M. B. Ahmad, N. A. Ibrahim, M. Z. Ab Rahman, K. Z. M. Dahlan, and W. M. Zin Wan Yunus, "Optimized conditions for the grafting reaction of poly (methyl acrylate) onto rubberwood fiber," Polymer international, vol. 53, no. 4, pp. 386-391, 2004.

[35] S. A. Abdel-Hafiz, "Potassium permanganate/thioureadioxide redox system-induced grafting of methacrylic acid onto loomstate cotton fabric," Journal of Applied Polymer Science, vol. 58, no. 11, pp. 2005-2011, 1995.

[36] S. Mishra, M. Misra, S. S. Tripathy, S. K. Nayak, and A. K. Mohanty, "Graft copolymerization of acrylonitrile on chemically modified sisal fibers," Macromolecular Materials and Engineering, vol. 286, no. 2, pp. 107-113, 2001.

[37] L. Rahman, S. Silong, W. M. Zin, M. Z. A. Rahman, M. Ahmad, and J. Haron, "Graft copolymerization of methyl acrylate onto sago starch using ceric ammonium nitrate as an initiator," Journal of Applied Polymer Science, vol. 76, no. 4, pp. 516523, 2000.

[38] A. M. Abulkibash, N. M. Osman, and F. A. Abuilaiwi, "Graft copolymerization of methyl acrylate onto date palm fiber and its application in the removal of chromium (III) from water," Desalination and Water Treatment, vol. 97, pp. 251-261, 2017.

[39] I. H. Mondal, "Grafting of methyl acrylate and methyl methacrylate onto jute fiber: physico-chemical characteristics of the grafted jute," Journal of Engineered Fibers and Fabrics, vol. 8, no. 3,2018

[40] S. Moharana and S. S. Tripathy, "Chemical modification of jute fibers. II: a study on the $\mathrm{Fe}^{2+} / \mathrm{H}_{2} \mathrm{O}_{2}$-initiated graft copolymerization of methyl methacrylate, acrylonitrile, and acrylamide onto jute fibers," Journal of Applied Polymer Science, vol. 42, no. 4, pp. 1001-1008, 1991. 
[41] F. A. Abuilaiwi, M. A. Atieh, M. B. Ahmad, N. A. Ibrahim, M. Z. A. Rahman, and W. M. Z. W. Yunus, "Preparation and characterization of polyamidoxime chelating resin from rubberwood fibre-g-polyacrylonitrile," Adsorption Science \& Technology, vol. 27, no. 7, pp. 661-670, 2009.

[42] S. K. Sahni and J. Reedijk, "Coordination chemistry of chelating resins and ion exchangers," Coordination Chemistry Reviews, vol. 59, pp. 1-139, 1984.

[43] P. Thilagavathy and T. Santhi, "Adsorption of Cr (VI) onto low-cost adsorbent developed from Acacia nilotica leaf activated with phosphoric acid: kinetic, equilibrium isotherm and thermodynamic studies," International Journal of Science and Research, vol. 3, no. 5, pp. 308-314, 2014.

[44] B. L. Rivas, A. M. Hernán, and V. Sandra, "Adsorption behavior of metal ions by amidoxime chelating resin," Journal of Applied Polymer Science, vol. 77, no. 9, pp. 19941999, 2000.

[45] M. Ghasemi, M. Naushad, N. Ghasemi, and Y. Khosravi-fard, "A novel agricultural waste based adsorbent for the removal of $\mathrm{Pb}$ (II) from aqueous solution: kinetics, equilibrium and thermodynamic studies," Journal of Industrial and Engineering Chemistry, vol. 20, no. 2, pp. 454-461, 2014.

[46] V. K. Gupta, I. Ali, T. A. Saleh, M. N. Siddiqui, and S. Agarwal, "Chromium removal from water by activated carbon developed from waste rubber tires," Environmental Science and Pollution Research, vol. 20, no. 3, pp. 1261-1268, 2013.

[47] M. Naushad, Z. A. ALOthman, and M. R. Khan, "Removal of malathion from aqueous solution using De-Acidite FF-IP resin and determination by UPLC-MS/MS: equilibrium, kinetics and thermodynamics studies," Talanta, vol. 115, pp. 15-23, 2013.

[48] Y. El Mouzdahir, A. Elmchaouri, R. Mahboub et al., "Interaction of stevensite with $\mathrm{Cd}^{2+}$ and $\mathrm{Pb}^{2+}$ in aqueous dispersions," Applied Clay Science, vol. 35, no. 1-2, pp. 47-58, 2007.

[49] A. Kumar, A. Singh, R. Yadav et al., "Adsorptive removal of $\mathrm{Hg}$ (II) from synthetic and real aqueous solutions using modified papaya seed," Journal of Dispersion Science and Technology, vol. 37, no. 11, pp. 1613-1622, 2016.

[50] B. Karagozoglu, M. Tasdemir, E. Demirbas, and M. Kobya, "The adsorption of basic dye (Astrazon Blue FGRL) from aqueous solutions onto sepiolite, fly ash and apricot shell activated carbon: kinetic and equilibrium studies," Journal of Hazardous Materials, vol. 147, no. 1-2, pp. 297-306, 2007.

[51] A. Elkamash, B. Elgammal, and A. Elsayed, "Preparation and evaluation of cerium (IV) tungstate powder as inorganic exchanger in sorption of cobalt and europium ions from aqueous solutions," Journal of Hazardous Materials, vol. 141, no. 3, pp. 719-728, 2007.

[52] A. R. Netzahuatl-Muñoz, F. . M. Guillén-Jiménez, B. ChávezGómez, T. L. Villegas-Garrido, and E. Cristiani-Urbina, "Kinetic study of the effect of $\mathrm{pH}$ on hexavalent and trivalent chromium removal from aqueous solution by Cupressus lusitanica bark," Water, Air, \& Soil Pollution, vol. 223, no. 2, pp. 625-641, 2012.

[53] Z. A. al-Othman, R. A. Ali, and M. Naushad, "Hexavalent chromium removal from aqueous medium by activated carbon prepared from peanut shell: adsorption kinetics, equilibrium and thermodynamic studies," Chemical Engineering Journal, vol. 184, pp. 238-247, 2012.
[54] I. Langmuir, "The constitution and fundamental properties of solids and liquids. Part I. Solids," Journal of the American Chemical Society, vol. 38, no. 11, pp. 2221-2295, 1916.

[55] T. W. Weber and R. K. Chakravorti, "Pore and solid diffusion models for fixed-bed adsorbers," AICHE Journal, vol. 20, no. 2, pp. 228-238, 1974.

[56] H. Kind, "About adsorption in solutions," Journal of Physical Chemistry, vol. 57, no. 1, pp. 385-470, 1907. 